International Journal of Instruction e-ISSN: 1308-1470 • www.e-iji.net
July $2019 \bullet$ Vol.12, No.3

p-ISSN: 1694-609X

pp. 183-200

Received: 03/08/2018

Revision: 24/03/2019

Accepted: 29/03/2019

OnlineFirst:23/04/2019

\title{
The Effect of Extended Wait-Time on Promoting Iranian EFL Learners' Willingness to Communicate
}

\section{Zahra Kamdideh}

Department of ELT, Ayatollah Amoli Branch, Islamic Azad University, Amol, Iran, z.kamdideh@gmail.com

\section{Hamed Barjesteh}

Department of ELT, Ayatollah Amoli Branch, Islamic Azad University, Amol, Iran, h.barjesteh@hotmail.com

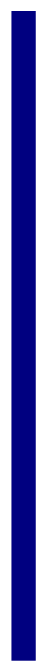

Increasing EFL learners' willingness to communicate has always been a concern to teachers. This study aimed at investigating the effect of extended wait time in EFL classrooms on the learners' willingness to communicate. In order to carry out this quasi-experimental study, 60 adult EFL learners at a basic level of proficiency in English (CEFR A1 and A2) were chosen to take part. They were first homogenised by Key English Test (KET) and then assigned to two groups of experimental and control. The Willingness to Communicate (WTC) Questionnaire by McIntyre, Baker, Clément, and Conrod (2001) was given $<<<$ to learners before the treatment. During the treatment phase, in the experimental group, the teacher allocated more wait time (3-5 seconds) to the learners when a question was asked, however, in the control group, wait time was limited (less than 3 seconds). After the treatment phase, the WTC questionnaire was administered again to find out if it altered as a result of the treatment. The results show that those learners who were in the experimental group showed higher willingness to communicate compared to lower WTC scores in the limited wait time group participants. The findings can make ELT teachers aware that giving their students more time to think can increase their willingness to communicate in the second language.

Keywords: extended wait time, willingness to communicate, foreign language learning anxiety, communication apprehension

\section{INTRODUCTION}

Much of the research on individual differences in second language (L2) acquisition has demonstrated the influence of affective variables, including attitudes, motivation, and language anxiety on achievement or proficiency. A recent addition to the affective constructs is willingness to communicate (WTC), which is emerging as a concept useful

Citation: Kamdideh, Z., \& Barhesteh, H. (2019). The Effect of Extended Wait-Time on Promoting Iranian EFL Learners' Willingness to Communicate. International Journal of Instruction, 12(3), 183200. https://doi.org/10.29333/iji.2019.12312a 
in accounting for individuals' first language (L1) and L2 communication. The concept, first developed in L1 communication by McCroskey and his associates (McCroskey, 1992; McCroskey and Richmond, 1987) was applied to L2 communication by MacIntyre and Charos (1996) and MacIntyre and Legatto (2010), in the Chinese context by Peng and Woodrow (2010), and on learners' perceptions and attitudes by de Saint Léger and Storch (2009).

Willingness to Communicate (WTC) is defined as "a readiness to enter into discourse at a particular time with specific person or persons using an L2," (MacIntyre, Clément, Dörnyei, and Noels, 1998, p. 547). To put it another way, WTC refers to the degree to which an individual is eager to participate in interaction with other people in various communication situations. MacIntyre and his colleagues (1998) also suggest that the ultimate and fundamental goal of language instruction should be to foster WTC in the L2. As MacIntyre, Baker, Clément, and Donovan (2002) suggest, the greater learners' WTC is, the more frequent communication in the L2 happens in the classroom. It can also encourage what Skehan (1989) refers to as a willingness to "talk in order to learn" (p. 48).

The concept WTC refers to the tendency of an individual to initiate communication when free to do so (McCroskey and Richmond, 1987, 1990). The concept could include communication in written forms, but this study focused on face-to-face communication or, more specifically, talking in a L2. Furthermore, Rowe (1974a) defines wait time as the amount of silent time a teacher allows to pass before and after a student response to a question. Rowe's research documented that teachers typically wait less than 30 seconds after asking a question before calling on students to respond. She argues that for many students, this provides little opportunity to process the question and formulate an answer.

Teachers are considered as one of the chief role-players in the classroom and they can have significant effects on teaching and learning processes that take place in the classroom. This means that teachers can be highly effective in making students willing or unwilling to talk in class. The WTC model, therefore, integrates affective, social, cognitive and situational variables as contributing factors to a person's willingness to communicate in the L2. A number of studies have been conducted to evaluate the efficiency of this relatively new concept. Some of these studies have concluded that an L2 learner's WTC will rise if they have a high opinion of their own second language competency and low communication anxiety (Clément, Baker, and MacIntyre, 2003). Recently, Clément et al. (2003) and Yashima (2002) combined these notions, i.e. perceived language competence and lack of communication anxiety in doing their studies in this regard. Likewise, there are some studies that argue that and L2 learner's motivation can be indirectly (MacIntyre and Charos, 1996) or directly (Baker and MacIntyre, 2000) related to their willingness to communicate.

The two key components of WTC are 'communication apprehension' and 'perceived communicative competence' (MacIntyre, 1994), which will be discussed here. Communication apprehension (language anxiety) and perceived competence have been argued by a number of researchers to predict WTC in both the L1 and the L2. 
In coping with the learners' anxiety, one of the things that L2 teachers can do to decrease anxiety of the learners in their classes is that they could increase the amount of wait-time for the learner to respond (Williams and Andrade, 2008). Furthermore, there have been some studies in the field of the amount of wait time on L2 learners' wait time such as that of Tsui (2001), who has investigated classroom interaction and found that "not giving enough wait-time for learners to process a question and formulate an answer is another reason for the lack of response from students" (p. 124). What the recent literature lacks in this field is that, to the best of the researcher's knowledge of the literature, none of the studies in the field of wait time have studied its effects on learners' willingness to communicate. Hence, this research paper is an attempt to merge these two fields of study with each other to find the possible effect of wait time on WTC.

Wait time has been investigated in the L2 classroom settings in recent decades. As an instance, Tsiplakides and Keramida (2009) investigated the use of some strategies for lowering anxiety in L2 classes. They suggest that implicit correction of errors, inclusion of humour, addressing students with first names, non-verbal praise such as patting on shoulders or giving a warm smile and sufficient wait time for answers can act as icebreakers and contribute to the fight against speaking anxiety.

In a critical analysis of the role of wait time in classroom interactions and the effects on student and teacher interactional behaviours, Ingram and Elliott (2016) examined the relationship between wait time and the interactional behaviour of teachers and students. They maintain that extending wait time can lead to a variety of changes in the norms of classroom interaction. They use the structures of interactions in formal classrooms to explain the previous findings relating to the extension of wait time. They also argue that different uses of extended wait time lead to different interactional norms and maintaining extended wait times may not be desirable.

Alavi, Pourhaji, and Yaghoubi (2016) analysed an EFL teacher's naturally-occurring interaction with learners during a homework review activity and how the teacher's extended wait-time practice afforded a learner the interactional space needed to initiate a question and voice her locus of trouble. They also argue that the teacher's consistent extended wait-time practice after the learner's initiation functions as an invitation bid for other learners to orient to the trouble and successfully negotiate it in their learner-learner interaction.

In investigating factors affecting WTC, Zarrinabadi (2014) conducted a qualitative study that utilized a focused essay technique to explore how teachers can affect learners' tendency to talk in class. He asked the participants to describe those situations in which teachers influenced their willingness to communicate in English. He received a total of 97 entries for situations in which the students were most willing to communicate and 84 entries for situations in which the students were least willing to communicate. He concluded that teachers' wait time, error correction, decision on the topic, and support exert influence on learners' WTC.

In another study by Noorbar and Mamaghani (2016), they studied the effect of codeswitching to L1, i.e. using the learners' mother tongue in the L2 classroom, on Iranian 
EFL learners' willingness to communicate, in addition to oral performance. They chose 60 EFL learners at CEFR A2 level of proficiency in English language for their study and measured their WTC before and after a 7-week treatment phase. They found that their learners' willingness to communicate increased significantly as affected by codeswitching. Similarly, Nazari and Allahyar (2012) looked at English as a Foreign Language (EFL) learners' willingness to communicate (WTC) as one of the predictors of their participation in classroom activities and L2 use in the classroom. A review of the literature highlights the potential role of teachers' discourse and interaction strategies as one of the causes of learners' WTC. Through reviewing the relevant literature and by deriving some insights into the relationship between language teacher talk and learners' opportunity to participate, the authors suggested ways in which teachers can intervene in their patterns of teacher-learner interaction to provide their learners with ample opportunities to volunteer ideas and to participate more in classroom activities.

\section{LITERATURE REVIEW}

\section{Wait Time}

To date, a number of research studies have been carried out on the significance of wait time on learning English as a foreign or second language. A researcher who has conducted many studies on wait time is Rowe (1974a, 1974b, 1978) who worked on the influence of some possibly effective variables through observing and tape-recording classes over six years. In her studies, she tried to understand why an 'inquisitional' pattern dominated interactions inside science classes under her study. In this respect, she took into account a number of variables, among them teacher's topical knowledge, materials, sample size, program types, student age, and pacing characteristics of various geographical areas. To her surprise, she found none of them as the chief reason behind.

Her study entitled 'Wait time and rewards as instructional variables, their influence in language, logic, and fate control' had two parts both published in 1974. In these series of studies, after she analysed more than 300 'intact classroom', as she puts it, tape recordings, she found out that the majority of them had common stable properties; the speed of teacher's teaching was very rapid. To put it other way, when a teacher wanted to ask a question, he/she tended to wait less than one second for students' responses in most cases. Also, if the student did not respond to that question, the teacher went on to repeat, rephrase or ask another question. S/he sometimes even called on another student. Thus, Rowe named the time of silence which followed teacher's question as wait-time I or post-solicitation wait-time. She noticed that mean wait-time I happens for one second.

Moreover, she found the second type of wait-time in another place. Wait-time II, which is also known as post-response wait-time, relates to a number of pauses students make and comes to an end when the teacher speaks. She detected that after a student responds to the teacher, s/he normally reacts or asks another question in an average time of nine/tenth of a second. Furthermore, she considered wait-time as a factor which impacts three teacher outcome variables. Her study showed that as soon as wait-time is extended and the behaviour is stabilized: 1. Teachers exhibit greater response flexibility as 
reflected by the occurrence of fewer discourse errors. 2. The number and kind of teacher questions change. 3. Teacher expectations for performance of students rated as relatively slow improves.

When these reports were first published, they paved the way for other researchers in the field to replicate Rowe's studies; some others considered new dimensions of the issue. I the same vein, some other scholars who were interested in her findings investigated wait-time as a dependent variable (e.g., Gambrell, 1983; Jones, 1980; Shrum, 1985), while others examined the effects of adapting wait-time, as an independent variable, on teacher and learner variables.

Rowe (1969) defined two types of wait time: wait time I was defined as the duration of the pause after a teacher utterance; and wait time II was defined as the duration of the pause after a student utterance. An extended or criterion wait time I and II was defined as an average of between 3 and 5 seconds. In most instances wait time I is related to the pause following a teacher question and wait time II is the pause after a student response to a question. In an endeavor to overcome difficulties encountered in implementing extended wait time I and II, Lake (1973) suggested that wait time should be redefined in terms of the period of silence that precedes teacher talk. Lake defined two types of wait time based on which speaker has primary control over the length of the pause. Teacher wait time was defined as the length of the pause preceding teacher talk. Student wait time was similarly defined as the length of the pause preceding student talk. Teacher or student talk can precede the relevant pause in either case.

Fowler (1975) has supported the conceptualization offered by Lake empirically in a study. In a factor analysis of six time-related variables, Fowler identified two factors he described as student-controlled silence and teacher-controlled silence. This outcome supports the decision to define wait time in terms of the person having primary control over the length of the silent pause. Fowler defined four types of wait time: teacher reaction wait time, student reaction wait time, teacher initiated wait time, and studentinitiated wait time. By partitioning wait time in this way a broad range of hypotheses can be tested. The definitions used by Fowler have considerable appeal for research on the manner in which silence is used by teachers and students. The potential for silent pauses to influence student learning quite likely depends on pause duration and the location of the pause with respect to teachers and students.

\section{Willingness to Communicate}

The concept WTC refers to the tendency of an individual to initiate communication when free to do so (McCroskey and Richmond, 1987, 1990). The concept could include communication in written forms, but this study focused on face-to-face communication or, more specifically, speaking in a second language.

The WTC model takes into consideration the effect of all social, cognitive, affective, and situational variables on a person's willingness to communicate in the L2. Although this is a recent model, many studies have been conducted to test its efficacy (Çetinkaya, 2007). Some of these studies have demonstrated that if L2 students have a high opinion of their language competency - perceived but not actual - and if they have low 
communication anxiety, their WTC in L2 soars (Clément, Baker, and MacIntyre, 2003). Recent studies by Clément, Baker, and MacIntyre (2003) and Yashima (2002) using the combined notions of perceived language competence and lack of communication anxiety demonstrated the linguistic self-confidence concept. Moreover, many other studies indicate that learners' motivation can be indirectly (MacIntyre and Charos, 1996) or directly (Baker and MacIntyre, 2000) related to their WTC. WTC consists of two fundamental aspects, i.e. Self-Perceived Communication Competence (SPCC) and Communication Apprehension. These two components are discussed in detail as follows.

\section{Self-Perceived Communicative Competence (SPCC)}

Self-Perceived Communicative Competence (SPCC) refers to a person's self-evaluation of their communication ability (McCroskey, 1982). The components contributing to SPCC will be discussed below with a closer look. Self-evaluative "beliefs are quite vital in deciding human activity especially [given that] humans tend to regulate the level and the distribution of effort spent vis-à-vis the effects expected from their actions" (Anyadubalu, 2010, p. 194); "people must feel sufficiently competent at the instrumental activities to achieve their desired outcomes" (Deci, 1995, p. 64). Anyadubalu (2010) found that higher self-evaluative feeling equalled lower anxiety and better performance and Hashimoto (2002, p. 57) found that an "increased perceived competence will lead to increased motivation which in turn affects frequency of L2 use in the classroom."

The role of culture and self-system in self-evaluation is an important one (Mercer, 2011) as it is "instrumental in . ..., motivation and in the regulation of interpersonal processes such as person perception, social comparison, and the seeking and shaping of social interaction" (Markus and Kitayama, 1991, p. 230). Markus and Kitayama believe that there are two self-views; the Independent, which is characteristic of North American and some other European cultures, and the Interdependent, characteristic of many Asian, African, South American and southern European cultures. Independent selves view the self as a distinct entity and seek to "discover and express [their] unique attributes" (1991, p. 226). They argue that interdependent selves:

"insist on the fundamental connectedness of human beings to each other [and recognize that] one's behaviour is determined, contingent on, and, to a large extent organized by what the actor perceives to be the thoughts, feelings, and actions of others in the relationship" (1991, p. 227).

While linked by self-view similarities, however, these geographically widespread cultures are clearly each unique; forming, maintaining and perpetuating their interdependent self-view in differing ways. Self-evaluative characteristics include "selfcriticism, self-discipline, effort, perseverance, the importance of others, shame and apologies, balance and emotional restraint" (Heine, Lehman, Markus, and Kitayama, 1999, p. 767); this leads to a concern and awareness of one's weaknesses as opposed to one's strengths. In education, this manifests itself as a hesitancy to assume superior proficiency than classmates (Heine, Takata, and Lehman, 2000) and a student awareness and concentration upon what is not yet known rather than knowledge already acquired 
(Aspinall, 2006). It is in fact "considered immature and bad manners for the learner to 'show off' something they have learned, or be ostentatious in any way" (Aspinall, 2006, p. 263). These cultural tendencies to self-critical and humble behaviour clearly have great implications for self-evaluation and classroom behaviour as they contribute to SPCC.

\section{Communication Apprehension (CA)}

Communication apprehension is defined by McCroskey and Baer (1985) as "an individual's level of fear or anxiety associated with either real or anticipated communication with another person or persons". CA has received extensive attention from both researchers and teachers in the U.S. over the past decade and is receiving similar attention from researchers in other cultures currently. A recently compiled bibliography lists over 800 published articles and conference papers focusing on CA and related constructs (Payne and Richmond, 1984).

Another more recent definition of CA is presented to the literature by Horwitz (2002) who defines CA as "anxiety or fear suffered by an individual of either actual or anticipated communication, with a group or a person, that can profoundly affect their oral communication, social skills, and self-esteem" (p. 1). The two definitions presented here pave the way for a more detailed discussion of CA.

Petry (2016) provides an example of a person who exhibits high communication apprehension. He states that when individuals with high CA are placed in any and every situation where they are required to speak, they experience the feeling. "This individual with high levels of CA would be categorized as having a trait-based apprehension as it is seen across multiple scenarios and situations" (p. 4). On the other hand, if a person shows a low level of CA, he/she is viewed as someone who does not have trait-based apprehension, however, when it comes to specific situations, they may experience moderate or high levels of CA. Going to interviews is an example of a situation where a person with low levels of CA goes to, where they might experience anxiety in response to the added pressure of performing for the interviewer.

What adds up to the concern with the communication apprehension, stems from its close association with another phenomenon, communication avoidance. This means that those who are apprehensive about communication, are very likely to plunge into communication avoidance and stop communication, which is a matter of concern in the process of L2 learning (McCroskey, Fayer, and Richmond, 1985). Hence, when a person experiences a high level of apprehension in communication, they are prone to avoiding communicating in that language.

\section{This Study}

Based on the above-mentioned information, the three main issues which are considered in this study are as follows:

First, there is the strong interdependence between interaction, input, output and the need for negotiation of meaning (Long, 1983; Willis, 1996). On the other hand, the need to pay more attention to the relationship between teacher talk and learning opportunity is 
important (Walsh, 2002). According to Ellis (2008, p. 216)," it is the teacher who is allowed to take part in all exchanges, to initiate them, to decide on the length of exchanges, to close exchanges, to include and exclude other participants." Therefore, any help, any scaffold and any sentence uttered by teacher may encourage learners to communicate more and more, and make longer discourses to continue the conversations in the classroom.

Second, if WTC is the ultimate goal of L2 instruction (Dörnyei, 2005), then unwillingness to communicate may be supposed as a barrier to communicate and any reason for this unwillingness such as anxiety, demotivation, not supporting teacher talk, etc. may be increased. Therefore, students' silence in the classroom may result in crucial problems in learning process.

Third, as mentioned above there will be a deep connection between teacher talk, especially the opportunities they give learners such as extending the wait time, and promotion of WTC in learners. On the other hand, it seems that there is a tendency to hold teacher-centered classes in Iran in which teachers usually speak more than learners in the classrooms. These kinds of classes and the language used by teachers may result in decreasing the opportunity of student involvement and interaction, increasing unwillingness to communicate and some other problems dealing with self-confidence. These problems may discourage students to complete learning process or continue it reluctantly.

Therefore, there is a gap in this area which shows that there has been no study carried out in the Iranian context on wait-time and WTC and their relationships, the present study was conducted to find out if extended wait time strategy can foster EFL students' WTC. Thus, the findings can be beneficial for L2 teachers who wonder how they can increase their students' willingness to communicate which will eventually lead to better learner-learner and learner-teacher interaction, and therefore better L2 learning. On the other hand, teachers can benefit from the findings of this study which attempts to find out if extended wait time gives way to educating L2 learners with a high rate of willingness to communicate. To comply with the objective, the following research question was proposed:

Does extended wait-time have a significant effect on promoting Iranian EFL learners' willingness to communicate?

\section{METHOD}

\section{Participants}

A sample of 60 Iranian female EFL learners was selected via convenience sampling to participate in this quasi-experimental study. The selection criteria was based on what learners were available to the researcher. They were studying English at Kish Mehr English Language Institute in Tehran, Iran. The participants were selected from basic level of English language proficiency (CEFR A1 and A2), and their age ranged from 18 to 28 , due to the fact that the sampling method was convenience sampling. After the administration of the homogeneity test, those whose score fell one standard deviation 
above and below the mean were selected to participate in the study. There remained 60 learners to take part in the study. They were divided into two groups of experimental and control.

\section{Instruments}

To conduct the present study the following instruments were employed:

\section{Key English Test (KET)}

2. Willingness to communicate (WTC) questionnaire

Key English Test (KET)

In the present study, the Cambridge Key English Test (KET) also known as 'Key', was used for homogenizing the participants regarding their English language proficiency level. KET is a basic level qualification -A2 on the Common European Framework of Reference- that shows learners can use English to communicate in simple situations. It shows learners have made a good start in learning English. The KET test which was used in this study consisted of 80 questions divided in 3 sections of reading, writing, and listening

Willingness to communicate (WTC) questionnaire

WTC questionnaire was used in order to measure the degree of WTC in the students (Appendix). The questionnaire was adapted from MacIntyre, Baker, Clément and Conrod (2001). The Scale measures L2 WTC in four basic skill areas: listening (8 items), speaking (5 items), reading (6 items), and writing (8 items). It also measures students' willingness to engage in L2 communication inside the classroom. This questionnaire includes 27 items and the students are asked to choose an answer based on the Likert scale from 1 to 5 . The scales are: 1) almost never willing, 2) sometimes willing, 3) willing half of the time, 4) usually willing and 5) almost always willing.

The questionnaire was administered to the learners two times: one before the treatment and one after the treatment. It is noteworthy that due to the fact that the participants of the current study were EFL learners at basic level of proficiency in English, the questionnaire was translated in their mother tongue, i.e. Persian in order to maximise understanding and minimise any possible misunderstanding.

\section{Data Collection Procedure}

Initially, to homogenize the participants with regard to their proficiency level, Cambridge Key English Test (KET) was administered to 70 students. 60 of them whose scores fell one standard deviation above and below the mean were selected. The participants were divided into two groups of experimental and control, each consisting of 30 participants. In addition, the WTC questionnaire was administered before the treatment began.

During the treatment phase, in the experimental group, the teacher extended the wait time to satisfy the criterion by Rowe (1969) who believed that an extended or criterion 
wait time I and II was defined as an average of between 3 and 5 seconds. However, this was not the case for the control group, and the wait time was below 3 seconds. In other words, the experimental group enjoyed an extended amount of wait-time I (postsolicitation wait-time) and wait-time II (post-response wait-time) when the need aroused in either of the two cases. As for the control group, none of the types of wait time (waittime I and wait-time II) were extended after solicitation (type I) and response (type 2).

After the treatment, the WTC questionnaire was administered again to find out about the possible changes in the learners' willingness to communicate caused by the treatment.

\section{Data Analysis}

The results of the pretest and posttest were compared with each other to find out the possible difference in result of the treatment. Then the data was analysed by SPSS for Windows through two paired-samples t-tests

\section{FINDINGS}

The purpose of this study was to find the possible effect of extended wait time on Iranian EFL learners' willingness to communicate. In order to answer research question, one-way ANCOVA procedure and post-hoc Bonferroni test were run on the data obtained from pretest and posttest. Before running the main statistical analysis of the present study, the assumptions of ANVOCA were examined, including presence of no significant outliers, normality of distribution, homogeneity of variances, and homogeneity of regression slopes. The results of the study and their interpretation are presented in the subsequent sections.

\section{ASSUMPTIONS}

Before data analysis, the assumptions of one-way ANCOVA, were tested. The first assumption was homogeneity of variances that was evaluated through running Leven's test.

Table 1

Levene's Test of Equality of Error Variances

\begin{tabular}{llll}
\hline Dependent Variable: & posttest & & \\
\hline F & df1 & df2 & Sig. \\
\hline .931 & 1 & 58 & .339 \\
\hline
\end{tabular}

The results of Levene's test revealed that the group variances were similar in WTC pretest because $\mathrm{p}$ value was greater than $.05(\mathrm{p}=.339)$. The Levene's test confirmed that the error variance of the dependent variable was equal across groups. The other assumption is that there should be no significant outliers. To test this hypothesis, the box plot of the data is presented in the following figure. 


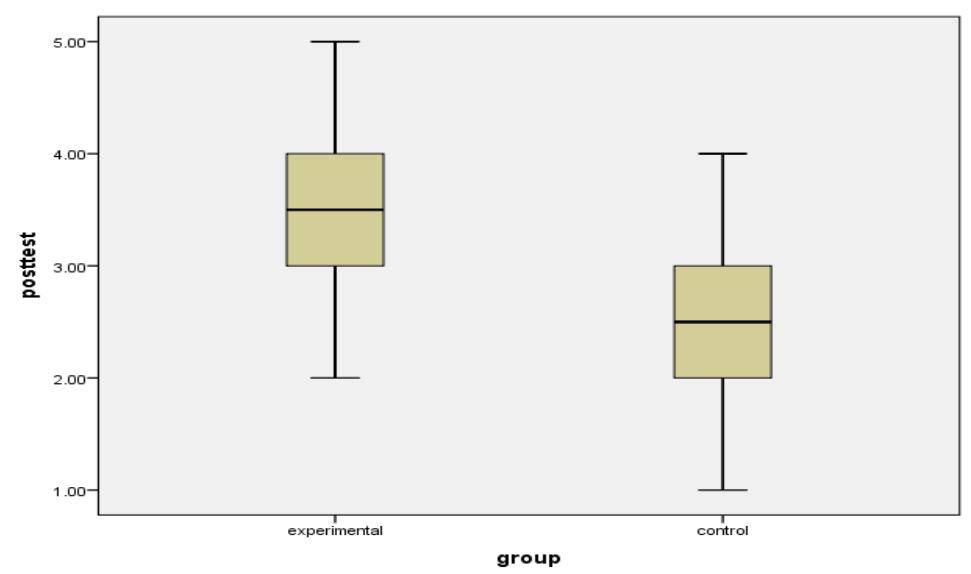

Figure 1

Box plot of posttest scores to find the possible outliers

Figure 1 shows that there are no outliers in the experimental and control groups, therefore the other assumption of ANCOVA procedure is met. The other assumption is normality of distribution which was tested through Shapiro-Wilk tests of normality the results of which is presented in Table 2 below.

Table 2

Test of normality of distribution

\begin{tabular}{lllllll}
\hline & \multicolumn{2}{l}{ Kolmogorov-Smirnov } & \multicolumn{4}{l}{ Shapiro-Wilk } \\
\cline { 2 - 7 } & Statistic & df & Sig. & Statistic & Df & Sig. \\
\hline Difference & .175 & 30 & .020 & .943 & 30 & .110 \\
\hline
\end{tabular}

By looking at Table 2, one can tell that the data are normally distributed. And this normal distribution is presented in Shapiro-Wilk column. The non-significant value for this test shows that the data are normally distributed among the participants of the current study. The last assumption is homogeneity of regression slopes which is presented in Table 3 below.

Table 3

Tests of Between-Subjects Effects

Dependent Variable: posttest

\begin{tabular}{llllll}
\hline Source & Type III Sum of Squares & df & Mean Square & F & Sig. \\
\hline Corrected Model & $22.567^{\mathrm{a}}$ & 3 & 7.522 & 5.541 & .002 \\
\hline Intercept & 70.473 & 1 & 70.473 & 51.916 & .000 \\
\hline Group & 1.152 & 1 & 1.152 & .849 & .361 \\
\hline Pretest & 10.208 & 1 & 10.208 & 7.520 & .008 \\
\hline group ${ }^{*}$ pretest & .208 & 1 & .208 & .153 & .697 \\
\hline Error & 76.017 & 56 & 1.357 & & \\
\hline Total & 799.000 & 60 & & & \\
\hline Corrected Total & 98.583 & 59 & & & \\
\hline
\end{tabular}

a. R Squared $=.229$ (Adjusted R Squared $=.188$ ) 
The Sig. level for the interaction (group*pretest) is greater than $.05(\mathrm{p}=.697)$. The value shows that the assumption of homogeneity of regression slopes has not been violated.

After the assumptions were met, the one-way ANCOVA test can be conducted. First, Table 4 below presents descriptive statistics (mean, standard deviation, number of participants) on the dependent variable, posttest, for the different levels of the independent variable, group.

Table 4

Descriptive Statistics

\begin{tabular}{llll}
\hline Dependent Variable: & posttest & & \\
\hline group & Mean & Std. Deviation & $\mathrm{N}$ \\
\hline experimental & 3.8667 & 1.04166 & 30 \\
\hline control & 2.9667 & 1.37674 & 30 \\
\hline Total & 3.4167 & 1.29263 & 60 \\
\hline
\end{tabular}

It is noteworthy that these values do not include any adjustments made by the use of a covariate in the analysis. Then the actual results of the ANCOVA are presented in the following table (Table 5).

Table 5

Tests of Between-Subjects Effects

Dependent Variable: posttest

\begin{tabular}{llllll}
\hline Source & Type III Sum of Squares & df & Mean Square & F & Sig. \\
\hline Corrected Model & $22.567^{\mathrm{a}}$ & 3 & 7.522 & 5.541 & .002 \\
\hline Intercept & 70.473 & 1 & 70.473 & 51.916 & .000 \\
\hline group & 10.208 & 1 & 10.208 & 7.520 & .008 \\
\hline pretest & 1.152 & 1 & 1.152 & .849 & .361 \\
\hline group ${ }^{*}$ pretest & .208 & 1 & .208 & .153 & .697 \\
\hline Error & 76.017 & 56 & 1.357 & & \\
\hline Total & 799.000 & 60 & & & \\
\hline Corrected Total & 98.583 & 59 & & & \\
\hline
\end{tabular}

a. R Squared $=.229$ (Adjusted R Squared $=.188$ )

Table 5 indicates whether the different interventions were statistically significantly different having adjusted for the covariate. The "Sig." column provides the statistical significance value of whether there are statistically significant differences in WTC posttest between the groups when adjusted for the pretest $(p<.05)$. To find out where the differences lie, the Bonferroni post-hoc test was conducted the results of which are presented in Table 6 below.

Table 6

Pairwise comparisons by Bonferroni test

Dependent Variable: posttest

\begin{tabular}{lllllll}
\hline \multirow{2}{*}{$\begin{array}{llll}\text { I) group } \\
\text { (J) group }\end{array}$} & $\begin{array}{l}\text { Mean Difference } \\
(\mathrm{I}-\mathrm{J})\end{array}$ & $\begin{array}{l}\text { Std. } \\
\text { Error }\end{array}$ & Sig. & \multicolumn{2}{l}{$\begin{array}{l}\text { 95\% Confidence Interval for } \\
\text { Difference }\end{array}$} \\
\hline experimental & control & $.900^{*}$ & .301 & .004 & .297 & 1.503 \\
\hline control & experimental & $-.900^{*}$ & .301 & .004 & -1.503 & -.297 \\
\hline
\end{tabular}


By consulting the significance values in the "Sig." column, it can be seen that the group comparisons are statistically significantly different. This means that the two experimental and control groups performed significantly different from each other when willingness to communicate is concerned. The positive number (.9) in the first row of comparison between the (experimental x control) groups shows that the experimental group outperformed the control group. Furthermore, the negative number (-.9) in the second row of the comparison between (control $x$ experimental) groups indicates the same results by showing that the control group performed significantly lower than the experimental group.

\section{DISCUSSION}

The present study was an attempt to investigate the effect of extended wait time on Iranian EFL learners' willingness to communicate. As the results of the study indicate, the learners who were treated with more wait-time outperformed those who had only below 3 second to think before the teacher moved on to another student or topic, or posed another question. Results indicate that if the teacher increased the wait-time she gave more opportunity to learners for learning to take place.

To put it differently, learners who were exposed to more wait time on the part of the teacher performed significantly better in their willingness to communicate. The significance of these findings is to make EFL teachers aware that increasing this wait time before the teacher asks another question or moves on to another student in the class can significantly increase willingness to communicate and lower foreign language learning anxiety level. This way, teachers can increase the efficacy of their classes.

Wherever the teacher waited more to get an answer from the students, this wait time contributed to lower anxieties on the part of the students, therefore increasing their willingness to communicate in the classroom. This high level of willingness to communicate, as discussed in detail in the previous sections, increases the chances of learning and uptaking the foreign language, as the literature suggests.

\section{CONCLUSION}

Therefore, it can be concluded that extending the wait time in case of a question asked in the classroom, the learners enjoyed a higher level of willingness to communicate. Hence, teachers are advised to extend the time between when a question is asked and another question is asked, or in some cases, an answer is provided. Based on the results of this study and those of others in the literature, it is advisable that extending wait time positively impacts lowering anxiety in L2 classrooms and increasing learners' willingness to communicate.

The pedagogical implications of this study can make EFL teachers aware of the fact that giving learners more time to think when a question is asked can foster their willingness to communicate, which in turn contributes to decreasing anxiety and learning the target language better. Therefore, the findings can contribute to the field of EFL/ESL in that lowering anxiety and increasing WTC have proved to ultimately boost language learning 


\section{REFERENCES}

Alavi, M., Pourhaji, M., \& Yaghoubi, B. (2016). Teacher Wait-Time and Learner Initiation: A Single Case Analysis. Journal of English Language Teaching and Learning, 8(18), 1-18.

AL-Nofaie, H. (2010). The attitudes of teachers and students towards using Arabic in EFL classrooms in Saudi public schools - a case study. Novitas-ROYAL (Research on Youth and Language), 4(1), 64-95.

Anyadubalu, C. C. (2010). Self-efficacy, anxiety, and performance in the English language among middle-school students in English language program in Satri Si Suriyothai School, Bangkok. International Journal of Human and Social Sciences, 5(3), 193-198.

Aspinall, R. (2006). Using the paradigm of 'small cultures' to explain policy failure in the case of foreign language education in Japan. Japan Forum, 18(2), 255-274.

Baker, S. C., \& MacIntyre, P. D. (2000).and second language orientation. Language learning, 50(2), 311- 371.

Çetinkaya B, Y. (2007). Turkish students' willingness to communicate in English. Dokuz Eylülüniversiy, Buca Education Faculty Journal, 21, 115- 123.

Clément, R., Baker, S.C., \& MacIntyre, P. D. (2003). Willingness to communicate in a second language: The effect of context, norms, and vitality. Journal of language and social psychology; 22(2), 190- 209.

de Saint Léger, D., \& Storch, N. (2009). Learners' perceptions and attitudes: Implications for willingness to communicate in an L2 classroom. System, 37(2), 269285 .

Fowler, T. W. (1975). An investigation of the teacher behaviour of wait-time during an inquiry science lesson. Paper presented at the annual meeting of the National Association for Research in Science Teaching, Los Angeles. (ERIC Document Reproduction Service No. ED 108 872).

Gambrell, L. B. (1983). The occurrence of think-time during reading comprehension instruction. Journal of Educational Research, 77(2), 77-80.

Heine, S.; Lehman, D.; Markus, H., \& Kitayama, S. (1999). Is there a universal need for positive self-regard? Psychological Review, 106(4), 766-794.

Heine, S., Takata, T., \& Lehman, D. (2000). Beyond self-presentation: Evidence for self-criticism among Japanese. Personality and Social Psychology Bulletin, 26(1), 71 78.

Horwitz, B. (2002). Communication apprehension: Origins and management. Albany, NY: Singular/Thomson Learning. 
Ingram, J., \& Elliott, V. (2016). A critical analysis of the role of wait time in classroom interactions and the effects on student and teacher interactional behaviours. Cambridge Journal of Education, 46(1), 37-53.

Jones, N. A. (1980). The effect of type and complexity of teacher questions on student response wait time. (Doctoral dissertation, University of Pittsburgh). Dissertation Abstracts International, 41(2), 529-537.

Lake, J. H. (1973). The influence of wait-time on the verbal dimensions of student inquiry behaviour. Dissertations Abstracts International, 34, 6476-A. (University Microfilm. No.7408866).

Liebscher, G., \& Dailey-O'cain, J. (2005). Learner code-switching in the content-based foreign language classroom. The Modern Language Journal, 89(2), 234-247.

MacIntyre, P. D., \& Blackie, R. A. (2012). Action control, motivated strategies, and integrative motivation as predictors of language learning affect and the intention to continue learning French. System, 36, 533-543.

MacIntyre, P. D., \& Legatto, J. J. (2010). A dynamic system approach to willingness to communicate: Developing an idiodynamic method to capture rapidly changing affect. Applied Linguistics, 32(2), 149-171.

MacIntyre, P. D., Baker, S. C., Clément, R., \& Conrod, S. (2001). Willingness to communicate, social support, and language-learning orientations of immersion students. Studies in second language acquisition, 23(03), 369-388.

MacIntyre, P. D. \& Charos, C. (1996). Personality, attitudes, and affect as predictors of second language communication. Journal of language and social psychology, 15(1), 326.

Markus, H., \& Kitayama, S. (1991). Culture and the self: Implications for cognition, emotion, and motivation. Psychological Review, 98(2), 224-253.

McCroskey, J. C. (1982). Communication competence and performance: A research and pedagogical perspective. Communication Education, 31(1), 1-7.

McCroskey, J. C., \& Baer, J. E. (1985). Willingness to communicate: The construct and its measurement.

McCroskey, J. C., \& Richmond, V. P. (1987). Willingness to communicate and interpersonal communication. In JC McCroskey \& JA Daly (Eds.), Personality and interpersonal communication (pp. 129-156).

McCroskey, J. C., \& Richmond, V. P. (1990). Willingness to communicate: Differing cultural perspectives. Southern Journal of Communication, 56(1), 72-77.

McCroskey, J. C., Fayer, J. M., \& Richmond, V. P. (1985). Don't speak to me in English: Communication apprehension in Puerto Rico. Communication Quarterly, 33(3), 185-192. 
McCroskey, J. C. (1992). Reliability and validity of the willingness to communicate scale. Communication Quarterly, 40, 16-25.

Mirhasani, A., \& Jafarpour-Mamaghani, H. (2009). Code switching and Iranian EFL Learners' Oral Proficiency. Journal of Teaching English as a Foreign Language and Literature, 1(2), 21-31.

Nazari, A., \& Allahyar, N. (2012). Increasing Willingness to Communicate among English as a Foreign Language (EFL) Students: effective teaching strategies. Investigations in university teaching and learning, 8, 18-29.

Noorbar, S., \& Mamaghani, H. J. (2016). The Effect of Code-Switching on Iranian Elementary EFL Learners' Oral Fluency, Accuracy, and Willingness to Communicate. English Language Teaching, 3(4), 103-75.

Olmo-castillo, W. N. (2014). Teachers' attitudes towards code switching within a bilingual classroom. (Master's thesis). Retrieved from http://digitalcommons.brockport.edu/cgi/viewcontent.cgi?article=1394\&context=ehd_th eses

Peng, J. E., \& Woodrow, L. (2010). Willingness to communicate in English: A model in the Chinese EFL classroom context. Language learning, 60(4), 834-876.

Petry, A. C. (2016). Communication Apprehension Affects Performance. Masters Essays. Paper 49-61.

Rahimi, A., \& Eftekhari, M. (2011). Psycholinguistic code switching in Iranian university classroom context. The Journal of Language Teaching and Learning, 1(1), 54-63.

Rowe, M. B. (1969). Science, soul and sanctions. Science and Children, 6(6), 11- 13.

Rowe, M. B. (1974a). Wait time and rewards as instructional variables, their influence in language, logic, and fate control: Part 1. Wait time. Journal of Research in Science Teaching, 11(2), 81-94.

Rowe, M. B. (1974b). Wait time and rewards as instructional variables, their influence in language, logic, and fate control: Part 2. Rewards. Journal of Research in Science Teaching, 11(4), 291-308.

Rowe, M. B. (1978). Teaching science as continuous inquiry: A basic, (2nd ed.). New York: McGraw-Hill.

Shrum, J. L. (1985). Wait time and student performance level in second language classrooms. Journal of Classroom Interaction, 20(1), 29-35.

Tsiplakides, I., \& Keramida, A. (2009). Helping students overcome foreign language speaking anxiety in the English classroom: Theoretical issues and practical recommendations. International Education Studies, 2(4), 39-48. 
Tsui, A. (2001). Classroom interaction. In: Carter, R., Nunan, D. (Eds.), The Cambridge Guide to Teaching English to Speakers of Other Languages. Cambridge University Press, Cambridge.

Walsh, S. (2002). Construction or obstruction: Teacher talk and learner involvement in the EFL classroom. Language teaching research, 6(1), 3-23.

Williams, K. E., \& Andrade, M. R. (2008). Foreign language learning anxiety in Japanese EFL university classes: Causes, coping, and locus of control. Electronic Journal of Foreign Language Teaching, 5(2), 181-191.

Yaqubi, B., \& Pourhaji Rokni, M. (2013). Teachers' limited wait-time practice and learners' participation opportunities in EFL classroom interaction. Journal of English Language Teaching and Learning, 4(10), 127-161.

Yashima, T. (2002). Willingness to communicate in a second language: The Japanese EFL context. The modern Language Journal, 86(1).54- 56.

Zarrinabadi, N. (2014). Communicating in a second language: Investigating the effect of teacher on learners' willingness to communicate. System, 42, 288-295.

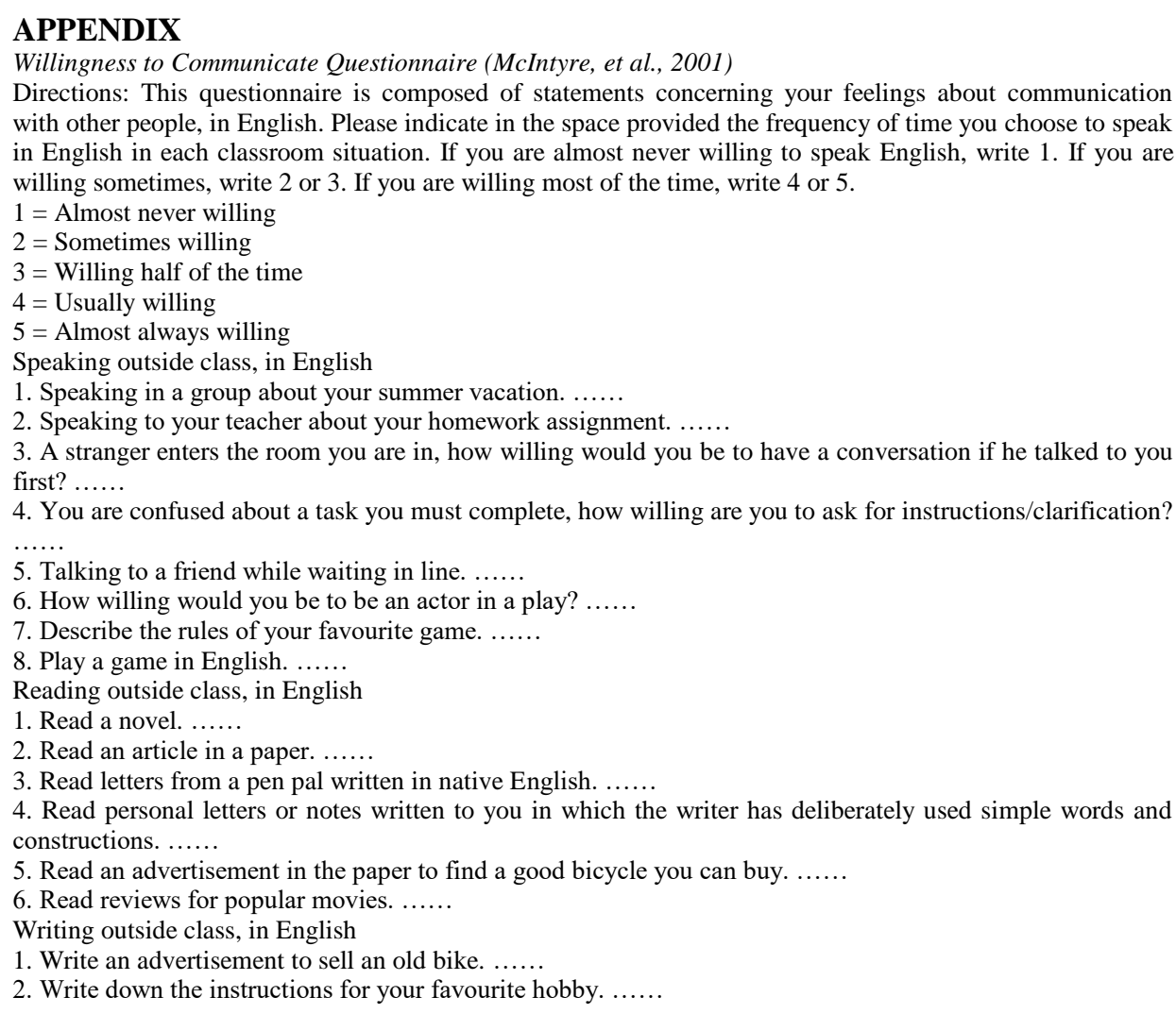


3. Write a report on your favourite animal and its habits......

4. Write a story.

5. Write a letter to a friend. ......

6. Write a newspaper article.

7. Write the answers to a "fun" quiz from a magazine. ......

8. Write down a list of things you must do tomorrow. ......

Comprehension outside class

1. Listen to instructions and complete a task. ......

2. Bake a cake if instructions were not in Persian. ......

3. Fill out an application form.

4. Take directions from an English speaker. ......

5. Understand an English movie. ......

Speaking in class, in English

1. Speaking in a group about your summer vacation. ......

2. Speaking to your teacher about your homework assignment. ......

3. A stranger enters the room you are in, how willing would you be to have a conversation if he talked to you first? .......

4. You are confused about a task you must complete, how willing are you to ask for instructions/clarification?

5. Talking to a friend while waiting in line. ......

6 . How willing would you be to be an actor in a play? ......

7. Describe the rules of your favourite game.

8. Play a game in English.

Reading in class, in English

1. Read a novel. ......

2. Read an article in a paper. ......

3. Read letters from a pen pal written in native English. ......

4. Read personal letters or notes written to you in which the writer has deliberately used simple words and constructions. .......

5. Read an advertisement in the paper to find a good bicycle you can buy. .....

6. Read reviews for popular movies.

Writing in class, in English

1. Write an advertisement to sell an old bike.

2. Write down the instructions for your favourite hobby.......

3. Write a report on your favourite animal and its habits.

4. Write a story.

5. Write a letter to a friend. ......

6. Write a newspaper article.

7. Write the answers to a "fun" quiz from a magazine. ......

8. Write down a list of things you must do tomorrow.

Comprehension in class

1. Listen to instructions and complete a task. ......

2. Bake a cake if instructions were not in Persian. ......

3. Fill out an application form.

4. Take directions from an English speaker. ......

5. Understand an English movie. ......

International Journal of Instruction, July $2019 \bullet$ Vol.12, No.3 